\title{
Treatment of acute, episodic asthma in preschool children using intermittent high dose inhaled steroids at home
}

\author{
N M Wilson, $M$ Silverman
}

\begin{abstract}
In a double blind, controlled trial, the effect of high dose beclomethasone dipropionate (750 $\mu \mathrm{g}$ three times daily for five days) administered by metered dose inhaler and valved spacer, was compared with placebo, during 70 paired episodes of acute asthma in 24 preschool children. Treatment commenced at home at the first sign of an attack. Parents' blind preference for active treatment was significant. Data from 17 pairs of treatment, however, were affected by interventions such as hospital admission or oral corticosteroid treatment. These events occurred similarly in active and control periods. An intrasubject comparison was made of diary scores from the 18 pairs of episodes in which no intervention occurred in either the active or placebo treatment. Both daytime and night symptoms over the first week of the attack were significantly reduced by active treatment. Intermittent high dose inhaled beclomethasone dipropionate is beneficial in modifying the severity of acute episodic asthma in preschool children able to use a spacer device.
\end{abstract}

The large and increasing number of preschool children admitted to hospital with acute asthma is a clear demonstration that treatment is unsatisfactory in this age group. ${ }^{12}$ In conjunction with inhaled bronchodilator treatment, corticosteroids have been the mainstay of treatment for acute attacks. Storr and colleagues showed that for children over 2 years old, a single dose of prednisolone was significantly better than placebo in the treatment of acute asthma presenting at a hospital casualty department. ${ }^{3}$ A third of their steroid treated group, however, required further steroid treatment. Some young children develop acute attacks of wheezing every three to four weeks in the winter and there is an understandable reluctance to use oral corticosteroids so often.

In order to overcome the problem of frequent oral corticosteroid courses in young children this study was designed to assess the effect of treating acute attacks of asthma with a five day course of high dose inhaled topical steroids, using a spacer device. The aim was to start treatment at the onset of any symptoms suggestive of the beginning of an acute wheezing episode.

Patients and methods PATIENTS

Thirty five children aged 1-5 years who had experienced at least two episodes of acute wheeze in the preceding three months, were recruited from the children's outpatient departments of Hammersmith, Ashford, and Ealing hospitals (table 1). The attacks were of sufficient severity to require bronchodilator treatment during the night on at least two occasions per episode. An additional requirement was that the child could use a Volumatic spacer (Allen and Hanbury) satisfactorily. Daily prophylactic treatment, if used, continued unaltered.

\section{TRIAL DESIGN}

A double blind intrasubject comparison was made of the effect of treatment with beclomethasone dipropionate $(250 \mu \mathrm{g} / \mathrm{puff})$ and an identical placebo inhaler. The dose used was three puffs (by a Volumatic spacer) taken three times a day for five days, giving a daily total dose of beclomethasone of $2 \cdot 25 \mathrm{mg}$. Children were given at least two puffs of a bronchodilator before each trial treatment. Trial inhalers were started at home when the parents recognised the first signs of an acute attack of asthma.

Each recruit was retained in the study until the next four acute episodes had occurred. The treatments were randomised in 'blocks' of two attacks, so that for each pair of attacks, one was treated with the active agent, and the other with the placebo inhaler. The treatment order was randomly determined.

Additional bronchodilator (up to eight puffs given over 10 minutes, or a nebulised aerosol) could be given as considered appropriate. In fact apart from the addition of the trial inhalers the parents and their doctors were encouraged to treat any ensuing symptoms as they had previously, with additional corticosteroids or hospital admission as considered necessary. Thus decoding was unnecessary at any stage during the study.

The parents were asked to record respiratory and systemic symptoms as well as additional treatment, for 14 days from the onset of each new attack, using the diary sheet provided. At the end of this time they recorded their opinion as to the effectiveness of the trial inhaler: helpful/did not help/don't know. The children were then examined in the outpatient clinic, so diaries could be checked and the next trial inhaler provided. For purposes of general management a note of any intercurrent symptoms was made in a separate diary. If any changes had been made to continuous prophylaxis between pairs of acute episodes, only the results obtained from pairs of treatments on the same day to day regime were used in the analysis. 
Table 1 Subject characteristics

\begin{tabular}{|c|c|c|c|c|c|c|c|}
\hline $\begin{array}{l}\text { Case } \\
\text { No }\end{array}$ & $\begin{array}{l}\text { Age } \\
\text { (years) }\end{array}$ & Sex & $\begin{array}{l}\text { No of attacks } \\
\text { in previous } \\
6 \text { months }\end{array}$ & $\begin{array}{l}\text { Admissions } \\
\text { in past } 1 \text { year }\end{array}$ & $\begin{array}{l}\text { Steroid courses } \\
\text { in past } 1 \text { year }\end{array}$ & $\begin{array}{l}\text { Prophylactic } \\
\text { treatment }\end{array}$ & $\begin{array}{l}\text { Home } \\
\text { nebuliser: }\end{array}$ \\
\hline $\begin{array}{r}1 \\
2 \\
3 \\
4 \\
5 \\
6 \\
7 \\
8 \\
9 \\
10 \\
11 \\
12 \\
13 \\
14 \\
15 \\
16 \\
17 \\
18 \\
19 \\
20 \\
21 \\
22 \\
23 \\
24\end{array}$ & $\begin{array}{l}1 \cdot 6 \\
2 \cdot 3 \\
4 \cdot 9 \\
2 \cdot 5 \\
2 \cdot 6 \\
4 \cdot 9 \\
4 \cdot 6 \\
2 \cdot 3 \\
4 \cdot 6 \\
4 \cdot 1 \\
2 \cdot 1 \\
3 \cdot 0 \\
4 \cdot 6 \\
3 \cdot 1 \\
3 \cdot 0 \\
3 \cdot 1 \\
3 \cdot 6 \\
3 \cdot 3 \\
4 \cdot 3 \\
4 \cdot 8 \\
3 \cdot 1 \\
4 \cdot 8 \\
4 \cdot 6 \\
3 \cdot 2\end{array}$ & 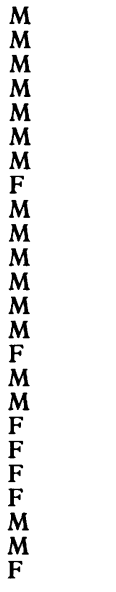 & $\begin{array}{r}5 \\
3 \\
2 \\
2 \\
3 \\
5 \\
5 \\
3 \\
2 \\
2 \\
7 \\
3 \\
11 \\
4 \\
5 \\
12 \\
33 \\
9 \\
6 \\
3 \\
10 \\
1 \\
8 \\
2\end{array}$ & $\begin{array}{r}11 \\
5 \\
2 \\
2 \\
3 \\
0 \\
0 \\
2 \\
2 \\
1 \\
8 \\
2 \\
0 \\
2 \\
1 \\
4 \\
2 \\
1 \\
2 \\
3 \\
3 \\
1 \\
2 \\
0\end{array}$ & $\begin{array}{l}1 \\
3 \\
3 \\
2 \\
2 \\
3 \\
3 \\
0 \\
1 \\
1 \\
2 \\
2 \\
0 \\
0 \\
3 \\
1 \\
0 \\
0 \\
2 \\
1 \\
4 \\
4 \\
2 \\
4 \\
3 \\
3 \\
3\end{array}$ & 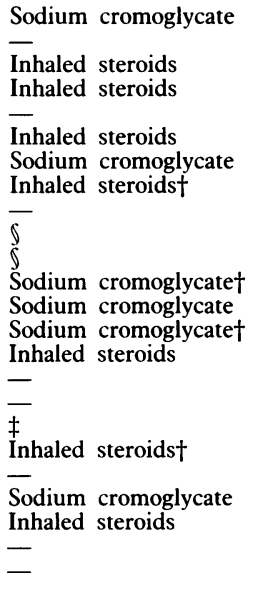 & $\begin{array}{l}+ \\
0 \\
0 \\
0 \\
+ \\
+ \\
+ \\
+ \\
0 \\
+ \\
+ \\
0 \\
+ \\
0 \\
0 \\
0 \\
+ \\
+ \\
+ \\
+ \\
+ \\
+ \\
0 \\
0\end{array}$ \\
\hline Mean & 3.5 & M:F 17:7 & $4 \cdot 6$ & $2 \cdot 04$ & $2 \cdot 9$ & & \\
\hline
\end{tabular}

"Yes, +; No, 0.

†Started sodium cromoglycate or inhaled steroids during trial for intercurrent symptoms.

$\ddagger$ Started sodium cromoglycate or inhaled steroids at end of trial for intercurrent symptoms.

†Started sodium cromoglycate or inhaled steroids at end of trial for intercurrent symptoms.
§reviously taken sodium cromoglycate or inhaled steroids but stopped as made no difference.

The outcome variables which were recorded for each episode included the need for hospital admission or oral corticosteroid treatment, daytime and night time symptom scores, additional bronchodilator usage and parents' assessment of the efficacy of the trial treatment.

Informed consent was obtained from a parent and the study had approval from the ethics committees of the three hospitals.

Paired $t$ tests or a $\chi^{2}$ test were used to compare the outcome of active and placebo treatments. Only completed pairs of treatments were used in the analysis.

\section{Results}

Twenty four children whose mean age was 3.5 years (table 1) completed 35 pairs of treatments. Thirteen recorded one pair each, the remainder completed two pairs. Their characteristics are shown in table 1 . A further 11 children failed to complete two episodes and were therefore excluded. Of these, six children did not experience two attacks of asthma during the two year trial period, despite their history (mean attack rate $2 \cdot 2$ episodes in the preceding three months). Another five subjects were withdrawn for social reasons: three because they moved out of the area and two whose parents were unable to cope with the protocol.

There was no measurable effect of active beclomethasone treatment on severe acute attacks, defined as those needing hospital admission or oral corticosteroid treatment (table 2). Numbers in each of these categories were rather small. Overall, significantly more parents considered beclomethasone to be helpful than reported benefit from the placebo inhaler $(\mathrm{p}<0.02)$.

A direct comparison between the diary scores of all active and placebo treated episodes was

Table 2 Comparison of episodes after treatment with beclomethasone and placebo

\begin{tabular}{|c|c|c|c|c|c|}
\hline & \multirow{2}{*}{$\begin{array}{l}\text { No of } \\
\text { admissions }\end{array}$} & \multirow{2}{*}{$\begin{array}{l}\text { No who had } \\
\text { steroids without } \\
\text { admission }\end{array}$} & \multicolumn{3}{|c|}{ Parents' opinion } \\
\hline & & & Helped & No help & Undetermined \\
\hline $\begin{array}{l}\text { Beclomethasone ( } n=35 \text { episodes }) \\
\text { Placebo ( } n=35 \text { episodes) }\end{array}$ & $\begin{array}{l}4 \\
4\end{array}$ & $\begin{array}{l}3 \\
6\end{array}$ & $\begin{array}{r}19 \\
9\end{array}$ & $\begin{array}{r}8 \\
18\end{array}$ & $\begin{array}{l}8 \\
8\end{array}$ \\
\hline Significance of difference & NS & NS & $\mathrm{p}<0.02^{*}$ & & \\
\hline
\end{tabular}

*Analysis was of discordant pairs only ( $n=30$ pairs).

Table 3 Comparison of mean scores during 18 pairs of active and placebo treated episodes in which neither a hospital admission nor treatment with oral steroids occurred

\begin{tabular}{|c|c|c|c|c|c|c|}
\hline & \multicolumn{3}{|l|}{ Nights } & \multicolumn{3}{|l|}{ Days } \\
\hline & $\begin{array}{l}\text { Duration of } \\
\text { symptoms } \\
\text { (days) }\end{array}$ & $\begin{array}{l}\text { Mean score } \\
\text { for first week }\end{array}$ & $\begin{array}{l}\text { No of nights } \\
\text { bronchodilators } \\
\text { given during } \\
\text { the night }\end{array}$ & $\begin{array}{l}\text { Duration of } \\
\text { symptoms } \\
\text { (days) }\end{array}$ & $\begin{array}{l}\text { Mean score } \\
\text { for first week }\end{array}$ & $\begin{array}{l}\text { No of days } \\
\text { bronchodilators } \\
\text { continued }\end{array}$ \\
\hline $\begin{array}{l}\text { Beclomethasone } \\
\text { Placebo }\end{array}$ & $\begin{array}{l}6 \cdot 1 \\
7 \cdot 56\end{array}$ & $\begin{array}{l}0.92 \\
1.36\end{array}$ & $\begin{array}{l}3 \cdot 38 \\
4 \cdot 95\end{array}$ & $\begin{array}{l}6 \cdot 11 \\
8 \cdot 38\end{array}$ & $\begin{array}{l}0 \cdot 82 \\
1 \cdot 24\end{array}$ & $\begin{array}{l}7 \cdot 0 \\
8 \cdot 05\end{array}$ \\
\hline $\begin{array}{l}\text { Difference }(\mathrm{SE}) \\
\text { Significance of difference }\end{array}$ & $\begin{array}{l}1.45(1.36) \\
p<0.5\end{array}$ & $\begin{array}{l}0.44(0.18) \\
p<0.05\end{array}$ & $\begin{array}{l}1.57(0.92) \\
p<0.5\end{array}$ & $\begin{array}{l}2 \cdot 27(1 \cdot 3) \\
\mathrm{p}<0 \cdot 1\end{array}$ & $\begin{array}{l}0.42(0 \cdot 16) \\
\mathrm{p}<0.02\end{array}$ & $\begin{array}{l}1.05(0.92) \\
p<0.5\end{array}$ \\
\hline
\end{tabular}


not possible because of the need for oral corticosteroids or hospital admission. There were 18 intervention free pairs of episodes and the mean results obtained from the diary scores of these 36 episodes are shown in table 3. All mean scores were lower and bronchodilator usage less prolonged after beclomethansone treatment, although a significant difference, using a paired $t$ test, was obtained only for the mean symptom score during the first week of the attack both for night $(p<0.05)$ and day $(\mathrm{p}<0.02)$.

There was no effect of treatment order on symptoms scores. The interval between attacks and therefore treatments varied and no carry over effect was looked for.

\section{Discussion}

The short term use of high dose inhaled steroids for acute childhood asthma has not previously been reported, although the instruction to adults to 'double your inhaler dose at the first warning of an attack' seems recently to have become standard. Our results show a small reduction in symptoms during acute episodes of asthma thus treated. Several reasons for these rather inconclusive results should be considered.

Firstly, the dose of beclomethasone chosen and duration of treatment were purely empirical. A longer treatment period could have been more beneficial, although it is customary to use three days of oral corticosteroid treatment for acute severe childhood asthma, and even a single dose can be adequate. ${ }^{3}$ Secondly, the young age of the children being treated might have meant that in the presence of airflow obstruction they were unable to open the spacer valve adequately. From subsequent personal observations of spacer use in this age group, this seems probable in some cases. An appropriate valved spacer for preschool children has yet to be designed. The device that we used is representative of those which are commonly available. Thirdly, the patients included in this study were hospital based and it is a possibility that less severely affected children might have received greater benefit from our therapeutic approach. Certainly beclomethasone appeared to have little effect on the development of the more severe attacks, as it did not reduce hospital admission rate.

The most pertinent criticism levelled at marginal or negative clinical trials is that they were too small to produce a confident result. In this study the number of episodes available for detailed analysis was reduced from 70 to 36 because of therapeutic intervention during one or both of the paired treatment periods. If the power of this study is calculated by taking a $50 \%$ reduction in symptoms as a clinically important result, ${ }^{4}$ then 18 pairs of treatments were sufficient to show a difference at the $5 \%$ level for both day and night mean symptom scores. A smaller improvement or a higher degree of significance would require larger numbers. At least 45 pairs of treated episodes, however, would be required to show a $50 \%$ reduction in the duration of symptoms or of bronchodilator usage, at the $5 \%$ level. So the marginal outcome of this trial can in part be explained by the relatively small number of episodes available for analysis. Detailed information about the natural history of acute episodic wheeze in this age group is not available. During the trial period there was a greater than anticipated reduction in the frequency of attacks and an increase in the variability in the response to viral infections in 3-4 year olds. This both reduced below our forecast the number of treated episodes and increased above our prediction the number needed to show a treatment difference. This age related change in symptomatology should be borne in mind in future clinical trials in preschool asthma.

The inadequacy of asthma diaries is recognised by all who attempt clinical trials in asthma. This trial was different from most as it was concerned with acute, and at times very severe symptoms only, in children who generally had prolonged symptom free periods. The scoring system would have perhaps more accurately described the situation if it had expanded the conventional 0-3 range used, to cater for the wide range of symptoms encountered. Also, it was impossible to make an accurate comparison of bronchodilator usage as a variety of dosages and methods of administration were used. The duration and not the amount of additional bronchodilator treatment was therefore used in the analysis and this may not have reflected the severity of the attack.

All except for one of the episodes was described as being associated with acute coryzal symptoms and in most cases fever was also present. This would support the view that acute asthma in this age group is precipitated by viral infections. ${ }^{5}$ Acute wheezing was a major feature in all the children but it is difficult to be certain how much of the symptomatology was additionally caused by bronchitis or post viral cough due to irritant receptor stimulation. The scoring system was not designed to differentiate between 'asthma' and 'non-asthma' symptoms that could coexist. The latter might not be expected to respond to steroid treatment and thus could mask the benefit to symptoms of asthma.

Despite many trials the efficacy of steroids in acute asthma of all ages remains controversial, ${ }^{6}$ although they are frequently used. Children under 18 months failed to show any benefit in one study but the subjects had been unwell for a mean of seven days before steroids were started. ${ }^{7}$ Early treatment has been advocated as being of greater benefit, although the trial on which this advice is based was not controlled. ${ }^{8}$ Storr $e t$ al also failed to show the benefit of a single dose of prednisolone in those under 2 years but showed some improvement in older children, ${ }^{3}$ as have others using short courses. ${ }^{9}{ }^{10}$ All the children in this study were over 18 months and there was no apparent age effect in the response to beclomethasone treatment. Other workers have failed to show any benefit either in children ${ }^{11}$ or in adults. ${ }^{12}$ As deaths from asthma have been attributed in part to delay in initiating steroid treatment ${ }^{13}$ one has to be careful that failure to show benefit is not simply the result of methodological problems rather than the result of a true lack of response. 
Intermittent, high dose, inhaled steroid treatment offers a new therapeutic approach to the troublesome condition of severe, episodic asthma in young children. Should it be recommended in addition to bronchodilator treatment? Over half of the children in the present study were taking or had tried continuous treatment with either sodium cromoglycate or inhaled steroids and yet they continued to have troublesome frequent attacks. Also, there was no evidence that intermittent high dose beclomethasone was more effective in those taking continuous treatment. Currently available prophylactic treatment is therefore unlikely to be the solution to prevention of acute asthma in this age group. The alternative is the use of single doses or short courses of oral corticosteroids and it remains to be answered whether these are more effective than inhaled topical steroids, and whether frequent oral courses carry any risk of significant adrenal suppression. The result of this trial demonstrated some benefit despite possible methodological problems. The early use of inhaled steroids does not preclude later use of single or repeated doses of oral corticosteroids, if severe symptoms develop. Because of possible difficulties with the use of the spacer device in the younger children, assessment of the use of intermittent high dose, nebulised corticosteroids in a larger study might be the next step forward in tackling the difficult problem of treating acute episodic wheeze in toddlers and preschool children.

We thank Dr Ros Jones and Dr John Chang (Ealing Hospital) and Dr Peter Husband (Ashford Hospital). The metered dose inhalers, suitably blinded, were provided by Glaxo Group Research. The study was supported by the Asthma Research Council.

1 Anderson HR. Is the prevalence of asthma changing? Arch Dis Child 1983;58:777-84.

2 Storr J, Barrell E, Lenney W. Rising asthma admissions and self referral. Arch Dis Child 1988;63:774-9.

3 Storr J, Barry W, Barrell E, Lenney W, Hatcher G. The effect of a single oral dose of prednisolone in acute childhood asthma. Lancet 1987; i:879-82.

4 Pocock SJ. The size of clinical trial. Clinical trials. Chichester: John Wiley, 1983: 123-33.

5 Minor. TE, Dick EC, De Meo AN, et al. Viruses as precipitants of asthmatic attacks in children. $\mathcal{F} A M A$ 1974;
227:292-8.

6 Weinberger $M$. Corticosteroids for exacerbation of asthma: current status of the controversy. Pediatrics 1988;81:726-9. wheezing attacks under 18 months. Arch Dis Child 1986;61: 15-9.

8 Brunette MC, Lands L, Thibodeau L-P. Childhood asthma: prevention of attacks with short-term corticosteroid treatment of upper respiratory tract infection. Pediatrics 1988; 81:624-9.

9 Deshpande A, McKenzie SA. Short course of steroids in home treatment of children with acute asthma. Br Med $\mathcal{f}$ home treatment of
1986;293:169-71.

10 Loren ML, Chai H, Leung P. Corticosteroids in the treatment of acute exacerbations of asthma. Ann Allergy 1980;45:67-71

11 Kattan M, Gurwitz D, Levison H. Corticosteroids in status asthmatics. F Pediatr 1980;96:596-9.

12 Luksza AR. Acute severe asthma treated without steroids. $\mathrm{Br}$ $\mathcal{f}$ Dis Chest 1982;76:15-9.

13 Kravis LP, Kolski GB. Unexpected death in childhood asthma. Am $\mathcal{J}$ Dis Child 1985;139:558-63. 